\title{
Learning support policy for mathematics in Irish primary schools: equal access but unequal needs
}

Joseph Travers*

St. Patrick’s College of Education, Drumcondra, Dublin, Ireland

This paper critiques learning-support policy for mathematics in Irish primary schools. The key policy question addressed is how equitable the development of the learning-support service has been in addressing low achievement in mathematics in designated schools compared to non-designated schools. The core argument developed is that there is a link between the Department of Education and Science policy in the Learning-Support Guidelines and inequitable access to learning support for mathematics between pupils in designated disadvantaged and non-designated schools.

Keywords: learning support; mathematics; disadvantage

\section{Introduction}

The focus of this paper is to critique learning-support policy for mathematics in Irish primary schools from the perspective of addressing low achievement. The critique uses an aspect of equity as a critical lens (National Council of Teachers of Mathematics (NCTM) 2005), with particular reference to educational disadvantage. A major focus of Irish government policy has been the targeting of resources in designated schools in areas of socio-economic disadvantage. Currently there is much concern about the extent of low achievement in mathematics in Ireland, particularly in schools designated as disadvantaged (Shiel et al. 2006). These are schools that receive additional support because of the level of social and educational disadvantage in the local catchment area. The indicators used in identifying such schools were the number of pupils whose families were living in local authority housing or nonpermanent accommodation, held medical cards, and were in receipt of unemployment benefit or assistance (Eivers, Shiel, and Shortt 2004). In 2002-2003 almost 10\% of primary schools were designated as disadvantaged (Eivers, Shiel, and Shortt 2004). The latest initiative under the title of DEIS (Delivering Equality of Opportunity in Schools) an action plan for educational inclusion (Department of Education and Science (DES) 2005a), aims to integrate eight existing programmes under a new programme called the School Support Programme (SSP). This programme will target 300 urban and 300 rural primary schools with concentrated levels of disadvantage.

The key policy question addressed in this paper is how equitable the development of the learning-support service has been in addressing low achievement in mathematics in designated schools compared to non-designated schools. A related

*Email: joe.travers@spd.dcu.ie 
question concerns the effects of the General Allocation Model (DES 2005b) on the same issue, which will be the focus of a further paper. The case will be made through a critique of key policy documents, research reports, evaluations and DES guidelines to schools.

Mathematics is a key subject in schools and acts as a major social filter (Schoenfeld 2002). Success in the subject is one of the best predictors for success in life (Lambe 1997). Concerns over standards in mathematics have been closely related to concerns over economic competitiveness and technological advances. Internationally, major shifts in mathematics curricula can be linked to initiatives to bolster economic goals. Mathematics has assumed a key social role in allowing access to careers in the scientific and technological arenas. The National Research Council (NRC) in the US outlines this function in the following terms:

\begin{abstract}
More than any other subject, mathematics filters students out of programs leading to scientific and professional careers. From high school through graduate school, the halflife of students in the mathematics pipeline is about one year; on average we lose half the students from mathematics each year, although various requirements hold some students in class temporarily for an extra term or a year. Mathematics is the worst curricular villain in driving students to failure in school. When mathematics acts as a filter, it not only filters students out of careers, but frequently out of school itself. (NRC 1989, 6)
\end{abstract}

In the US the negative consequences of this filtering were not equally distributed (NRC 1989). Schoenfeld (2002) building on arguments of Moses (2001) suggests that mathematics education is a civil rights issue. He cites Moses, who argues that:

Today ... the most urgent social issue affecting poor people and people of color is economic access. In today's world, economic access and full citizenship depend on math and science literacy. I believe that the absence of math literacy in urban and rural communities throughout this country is an issue as urgent as the lack of Black voters in Mississippi was in 1961. (Cited in Schoenfeld 2002, 5)

There is substantial evidence that failure to acquire basic skills in numeracy and literacy is often followed by a school career of low achievement, grade retention, disruptive behaviour, absenteeism, suspension and early school leaving (Eivers, Ryan, and Brinkley 2000). Mathematics also presents difficulties for those who reach third level education. In a recent study of non-completion in undergraduate courses in Ireland, Morgan, Flanagan, and Kellaghan (2001) found that the largest numbers of students dropped out of courses that required mathematical knowledge. Given this evidence it is vital that pupils experiencing difficulties can have these addressed through access to quality learning support. The following section analyses such access in the Irish primary school system.

\title{
Access to learning support in mathematics
}

To support the argument concerning pupils in schools in disadvantaged areas and lack of access to learning support in mathematics, it is necessary to examine the findings of a major evaluation of the learning-support service in 1998 and the way its recommendations were prioritised and implemented. The Educational Research Centre's (ERC) evaluation of the then remedial service, Study of Remedial Education in Irish Schools (SRE) (Shiel and Morgan 1998) was the first systematic examination 
of the service since its instigation in the 1960s. The report estimated, mainly based on feedback from school principals, that some $19 \%$ of pupils had serious difficulties in mathematics in schools in disadvantaged areas. However, only $41 \%$ of schools had access to learning support in mathematics supporting just $2.5 \%$ of pupils across all schools. In addition, despite significantly lower attainment levels across all six primary grades $\left(1^{\text {st }}-6^{\text {th }}\right)$ there was little difference in the percentage of schools offering learning support in mathematics based on whether they were designated schools (41.2\%) or not (40.6\%). Butler (2005) in a small-scale survey of 30 learningsupport teachers also found low provision for mathematics. Mc Carthy and Burns (2005) make the point that mathematics has been the 'Cinderella' of learning support in Ireland.

In spite of the recommendation from the DES that the results of standardised and criterion referenced tests be used in selecting pupils for learning support, the most important factor used by schools $(51.1 \%)$ was the recommendation of the class teacher. This ensured that local rather than national norms were used to select pupils, resulting in schools with pupils with higher achievement levels, having corresponding higher achievement levels among the pupils selected for learning support (Shiel and Morgan 1998). In their recommendations the report authors suggested that:

The provision of remedial teaching to pupils with learning difficulties in mathematics should be extended on a phased basis (for example, over five years), during which time attention should also be given to (a) the effects of implementing agreed/revised guidelines in the selection of pupils for remedial teaching in English and the continuation of pupils in remedial classes; (b) the effects of implementing more intensive early intervention programmes in English; (c) the creation of additional sanctioned posts in schools/clusters in which provision is deemed to be insufficient; (d) the provision of ongoing in-service training to remedial teachers on the diagnosis and remediation of learning difficulties in mathematics; (e) an examination of the effects of remedial teaching in mathematics; and (f) a consideration of the possibility of integrating remedial teaching in English and mathematics for pupils in the early years of primary school. (Shiel and Morgan 1998, xxv-xxvi)

The recommendations did not however suggest a prioritisation of support in schools designated as disadvantaged. Meanwhile the case for change was being fuelled by additional evidence.

Disparities in achievement and provision

Further evidence of disparities in achievement between schools and inequities in access to learning support became apparent in a national assessment of the mathematics achievement of pupils in $4^{\text {th }}$ class (aged 9-10) in primary schools. Such assessments are completed for literacy and mathematics every five years in the Irish system. The 1999 National Assessment of Mathematics Achievement (Shiel and Kelly 2001) reported that the mean mathematics achievement score of pupils attending schools designated as disadvantaged was significantly lower, by about one half of a standard deviation, than that of pupils attending non-designated schools. Furthermore, more than twice as many pupils in designated disadvantaged schools (20\%) as in non-designated schools (8\%) performed at or below the $10^{\text {th }}$ percentile for the population. According to class teachers, $16 \%$ of pupils in $4^{\text {th }}$ class were in 
receipt of learning support in English from a sanctioned learning-support teacher, while $7 \%$ were in receipt of such support in mathematics.

In its recommendations, the study was a little uncertain in how to address the issue of low achievement in mathematics and the provision of learning support, interpreting the disparity in terms of lack of resources to provide adequate support or also a lack of commitment to mathematics, over and above English, as a subject requiring additional support (Shiel and Kelly 2001, 75). However, it does not spell out the implications of this for schools where the needs in English have reduced and where they have not. In fact it seems to suggest that the imbalance may lie with school practices, rather than DES policy. For example, it states that:

The Learning-Support Guidelines (Department of Education and Science 2000) make no distinction between English reading and mathematics in suggesting who should be selected for supplementary teaching: 'Priority should be given to pupils who are performing at or below the $10^{\text {th }}$ percentile in English reading and/or mathematics'. (Shiel and Kelly 2001, 75)

Policy response to evaluations of learning support

As a result of the SRE report (Shiel and Morgan 1998) the Department of Education and Science (2000) issued very comprehensive new guidelines on learning support. There was an emphasis on whole-school policies, early intervention, collaboration and the direction of resources towards pupils in greatest need. Additional teacher appointments were made to ensure all schools had access to the learning-support service for the first time. In relation to mathematics I would argue that there is ambiguity in the guidelines, which results in pupils in the most disadvantaged schools losing out in learning support for this subject. The guidelines outline that the aim of the learning-support service is to 'ensure that all pupils achieve basic literacy and numeracy by the time they complete their primary education' (DES 2000, 14). In the section on principles of learning support it states that the drawing up of policies, systems and supports for pupils with 'low achievement in English and mathematics' is one of these principles. In terms of outcomes, the achievement of adequate levels of competency 'in literacy and mathematics' is clearly stated (DES 2000, 16).

However, when it comes to actually providing learning-support programmes the emphasis changes to 'those pupils who are performing at or below the $10^{\text {th }}$ percentile on nationally standardised tests of English and/or mathematics' (DES 2000, 15). Further it states as a 'subsidiary aim' the provision of 'supplementary teaching and additional support and resources for pupils in English or mathematics'. The change from 'English and mathematics' to 'English and/or mathematics' to 'English or mathematics' is highly significant [emphasis added]. This effectively allows schools a let-out clause in relation to mathematics and provides the DES with a let-out clause in terms of meeting the needs of all pupils who are low achievers in mathematics. That this is the case becomes clearer as further advice in the guidelines is analysed.

In a section on the selection of pupils for supplementary teaching the guidelines state:

Supplementary teaching should be made available to pupils with low achievement in mathematics. Schools that do not provide such a service should introduce it on a phased 
basis over a period of two to three years as the school's needs in English are reduced.

(DES 2000, 58) [emphasis added]

While Shiel and Kelly (2001) and Surgenor and Shiel $(2008,107)$ refer to 'the implied equivalence of English and mathematics in the Learning-Support Guidelines', this suggests a prioritisation of English. The above advice needs to be interpreted in the following significant context. It was a finding from the SRE report that many nondesignated schools were providing supplementary teaching in English to pupils of average and above average reading ability, while other pupils in the schools had severe difficulties in mathematics but no provision for them. Such schools were clearly in a position to take up the above advice and switch some resources to mathematics. This was less the case in disadvantaged areas where the needs in English are more acute and require greater levels of resources.

Interpreting the above advice from the Learning-Support Guidelines in this wider context, one can see that it advantages pupils in schools in non-disadvantaged areas. It is in these schools, mainly, for the foreseeable future that the needs in English are more likely to reduce, as attainment levels are higher than in designated schools. It is in these schools that the learning-support teachers can turn to mathematics, and disproportionately more pupils in need will receive help, than in schools beset with literacy difficulties in disadvantaged areas. The Learning-Support Guidelines make no distinction between the different needs of schools in designated disadvantaged contexts and other schools.

Equal access but unequal needs

Evidence of this disproportionate access to learning support for mathematics between designated and non-designated schools is apparent in the findings of The 1999 National Assessment of Mathematics Achievement. Given the figures on the proportions of pupils in designated disadvantaged schools performing at or below the $10^{\text {th }}$ percentile one would expect that they would differ significantly in the amount of learning support received in mathematics. However, Shiel and Kelly (2001, 71) found that 'the proportions of pupils in designated disadvantaged schools (10\%) and non-designated schools (7\%) who were in receipt of learning support in mathematics did not differ significantly'.

Further evidence of lack of access to support for mathematics arose in a recent evaluation by the Inspectorate of literacy and numeracy in disadvantaged schools (DES 2005b). Twelve schools were selected from among one hundred schools with the highest reported levels of disadvantage in the Republic of Ireland. In half the schools, inspectors reported that learning-support provision was not available for pupils with learning needs in numeracy. The reported recommended that:

Where disadvantaged schools can demonstrate an inability to provide learning support in mathematics because of the size of the caseload for learning support in English, The Department of Education and Science should consider what further supports need to be put in place in the school. (DES 2005b, 66)

This could be interpreted as an acknowledgement of how the extent of the needs in English may hinder such schools in providing support for difficulties in mathematics. 
The 2004 National Assessment of Mathematics Achievement

In The 2004 National Assessment of Mathematics Achievement (Shiel et al. 2006), part of the survey addressed learning support in mathematics. It was completed six years after the major Survey of Remedial Education in Ireland, five years after the introduction of the revised primary school curriculum, four years after the publication of the Learning-Support Guidelines and the expansion of the learningsupport service to all primary schools.

One hundred and seventy two respondents completed the Learning-Support Teachers' Questionnaire. Of these 35.5\% provided learning support in English only, $2.9 \%$ for mathematics only and $61.6 \%$ provided support in both subjects. Half of the pupils attended schools in which learning support was provided (Shiel et al. 2006). As in 1999 similar percentages (nearly 7\%) were receiving learning support across both school types, designated and non-designated. Similarly, for pupils with more serious difficulties, over twice the percentage in designated schools (19\%) than in non-designated schools (8\%) were judged in need of resource teaching in mathematics because of a learning disability, yet this was not reflected in terms of actual provision which was $7.5 \%$ and $5.3 \%$ respectively. In their summary report, the authors note an improvement in access to support in mathematics since the earlier research in 1999. However, it is also the case that from 1999 the resource teacher service expanded considerably and a large number of the children accessing this service would have previously attended special classes and schools outside the remit of the 1999 study. In addition the report found the following:

- Just over one half of pupils attended schools in which no learning support is provided.

- There was still no difference between the level of support in designated and non-designated schools despite a huge differential in achievement levels (26\% of pupils in designated schools achieved scores at or below the 10th percentile, as against $8 \%$ in non-designated schools).

- The percentage of pupils attending schools in which learning support for mathematics was provided was almost twice as large in non-designated (54.2\%) as in designated (26\%) schools.

- Whereas in 1999, 47.9\% of designated schools provided learning support in mathematics, by 2004 this had decreased to $26 \%$.

These findings lend weight to the argument that DES policy from 2000 onwards contributed to proportionately less pupils in need of support in designated schools getting access to learning support in mathematics than in non-designated schools.

Of the learning-support teachers providing support in mathematics only $25 \%$ of their time and caseload was devoted to the subject. In addition, in contrast to support in English, provision was lowest in the junior end of the schools and highest in the senior classes. Again, it can be argued that this lack of attention to early intervention has a significantly greater negative impact in designated schools as achievement levels between pupils in early mathematics can differ by up to three years starting school and widens when no intervention is put in place (Griffin, Case and Siegler 1994).

In line with the recommendations of the revised primary school mathematics curriculum (DES 1999) there was a significant decrease of 48 minutes per week in 
single-grade classes in the time allocated to mathematics instruction, resulting in an overall average of three hours 36 minutes instruction per week. This contrasts with the numeracy hour in England for example, which gives pupils an additional one hour 24 minutes on average per week in mathematics instruction compared to Irish schools (Department for Education and Employment (DfEE) 1999). It is reasonable to assume that this reduction since 1999 disproportionately disadvantages the weakest pupils in the system, as 'time on task is an important predictor of achievement' (Kellaghan 2002, 26). This time allocation could decrease further as the revised primary curriculum guidelines recommends two and a half hours with some discretionary time bringing this up to three hours per week (DES 1999). It is significant and a further validation of the case being made that the percentage of pupils performing under the $10^{\text {th }}$ percentile in designated schools increased from $20 \%$ to $26 \%$ from the 1999 to 2004 study, while the figure in non-designated schools remained at 8\% (Shiel and Kelly 2001; Shiel et al. 2006).

The latest policy initiative, the General Allocation Model (GAM), continues the ambiguity in relation to learning support for mathematics. It states that in determining eligibility for learning-support teaching, priority should be given to pupils whose achievement is at or below the $10^{\text {th }}$ percentile on standardised tests of reading or mathematics' (DES 2005c, 3) and that 'the development of literacy and numeracy skills will be a major component of many interventions at stages II and III'. However, it also states that:

In drawing up whole-school policies and procedures, teachers and schools should follow the guidance provided in the Learning-Support Guidelines, particularly in relation to whole-school planning, partnership, screening, selection, assessment and review, and planning and teaching. (DES 2005c, 5)

The conflict between the prioritising of literacy support in the Learning-Support Guidelines and the intention of the GAM are not addressed. The circular does not state that all pupils with learning needs in mathematics below a certain threshold are entitled to additional support.

The effects of interventions in disadvantaged schools on mathematical achievement

A counter argument could be advanced that designated disadvantaged schools have lower pupil teacher ratios, enhanced capitation grants and are part of national schemes to combat disadvantage. However, there is no data suggesting a reduction in the achievement gap between such schools and those in non-disadvantaged areas. In fact the opposite is the case with the gap getting wider in terms of literacy and mathematical achievement.

To support this conclusion it is necessary to analyse the findings of the most recent evaluations of initiatives to combat disadvantage in schools. One such major initiative was the introduction of Breaking the Cycle in 1996 signalling the formal introduction within the DES of positive discrimination in favour of pupils from disadvantaged backgrounds, with specific focus on large-scale urban disadvantage and, for the first time, on rural and dispersed disadvantage. It included increased emphasis on in-career development for all staff members of the participating schools, particularly through the development of a school development plan and training and support for teachers to enable them to adapt their teaching practice to meet the 
needs of their pupils. Junior classes in the schools were reduced to 15 pupils and a home-school-community liaison teacher (HSCL) was also provided.

Weir (2003) carried out the evaluation of this initiative. As can be seen from Table 1 the mean raw score of pupils in the Breaking the Cycle schools worsened over the period of the scheme. The percentile rank of the mean for these pupils in 2003 was 14. It was well over one standard deviation below the national mean. Pupil achievement was significantly lower than in 1997 at the start of the initiative $(\mathrm{t}=5.2$; $\mathrm{df}=1004$; p B.001) (Weir 2003). As a consequence of this deterioration in mathematical standards in these schools, the percentage of pupils scoring below the $10^{\text {th }}$ percentile had increased from $35.5 \%$ in 1997 to $45.6 \%$ in 2003 . These results did not include $7.7 \%$ of pupils deemed by their teachers to be too weak in mathematics to sit the test. The inspectorate in their evaluation of 12 disadvantaged schools found $73 \%$ of the pupils in the final two grades of primary school had scores on standardised numeracy tests at or below the $20^{\text {th }}$ percentile (DES 2005c).

Likewise, a recent review of Early Start, the very limited state involvement in preschool education in some disadvantaged areas, found that it did not emphasise early numeracy (Lewis and Archer 2003), while another evaluation found that number work was being inappropriately dealt with in traveller pre-schools (DES 2003). These findings are important in light of key knowledge from the literature on disparities in achievement levels in early mathematics between children from different socioeconomic backgrounds and the role of early intervention in eliminating these differences (Griffin, Case and Siegler 1994). It is hoped that the numeracy initiatives under the DEIS programme (DES 2005a) will go some way to addressing some of these issues.

\section{Conclusion}

Thus, this critique has identified a link between DES policy in the Learning-Support Guidelines and inequitable access to learning support for mathematics between pupils in designated disadvantaged and non-designated schools. Such access is crucial as one element of tackling differences in mathematics achievement between these school contexts. Volmink $(1994,51)$ argues that:

Mathematics is not only an impenetrable mystery to many, but has also, more than any other subject, been cast in the role as an 'objective' judge, in order to decide who in the society 'can' and 'cannot'. It therefore served as the gatekeeper to participation in the decision-making processes of society.

Table 1. Means and standard deviations (raw scores) of $6^{\text {th }}$ class pupils in Breaking the Cycle schools in 1997, 2000, and 2003, and a national sample on level six of the Drumcondra Primary Mathematics Test.

Breaking the Cycle

\begin{tabular}{lccc}
\hline 1997 & 2000 & 2003 & National Sample 2003 \\
\hline $\mathrm{M}=42.90$ & $\mathrm{M}=38.65$ & $\mathrm{M}=37.78$ & $\mathrm{M}=58.72$ \\
$\mathrm{SD}=16.45$ & $\mathrm{SD}=14.17$ & $\mathrm{SD}=13.45$ & $\mathrm{SD}=17.88$ \\
$(\mathrm{~N}=605)$ & $(\mathrm{N}=479)$ & $(\mathrm{N}=401)$ & \\
\hline
\end{tabular}

Source: Weir, 2003 
A component of equity applied to mathematics (NCTM 2005) is differentiated support based on need. The Learning-Support Guidelines should state categorically that all pupils with low achievement in mathematics are entitled to appropriate and equitable support. While there is merit in the argument of raising the criterion threshold for support up to the $20^{\text {th }}$ percentile, unless this is accompanied by the required resources in designated schools this could lead to a further widening of the achievement gap between pupils in designated and non-designated schools. The National Council for Special Education (NCSE 2006, 17) in its implementation report for the Education for Persons with Special Educational Needs Act (EPSEN) (Government of Ireland, 2004) suggests that there is 'almost an endemic fascination with inputs' in the Irish system. However, this emphasis on inputs is understandable when inequities in resource allocation and access are uncovered. When such inequities are addressed the focus of attention could then shift to monitoring pupil progress and evaluating the efficacy of the use of additional resources. A key issue is whether the recent policy change of the General Allocation Model addresses this situation (DES 2005c).

\section{Notes on contributor}

Dr Joseph Travers is Director of Special Education, St. Patrick's College, Drumcondra. He is a former primary school teacher (mainstream, special class, learning support/resource).

\section{References}

Butler, L. 2005. Mathematics learning support in Irish primary schools: A study. In Proceedings of First National Conference on Research in Mathematics Education, ed. S. Close, T. Dooley and D. Corcoran, 318-29. Dublin: St. Patrick's College.

Department of Education and Science. 1999. Primary curriculum: An introduction. Dublin: The Stationery Office.

Department of Education and Science. 2000. Learning-support guidelines. Dublin: The Stationery Office.

Department of Education and Science. 2003. Preschools for travellers: National evaluation report. Dublin: The Stationery Office.

Department of Education and Science. 2005a. DEIS (Delivering equality of opportunity in schools): An action plan for educational inclusion. Dublin: Department of Education and Science.

Department of Education and Science. 2005b. The organisation of teaching resources for pupils who need additional support in mainstream primary schools. Circular 02/05. Dublin: Department of Education and Science.

Department of Education and Science. 2005c. Literacy and numeracy in disadvantaged schools: Challenges for teachers and learners (LANDS). Dublin: The Stationery Office.

DfEE. 1999. The national numeracy strategy. Sudbury, UK: DfEE Publications.

Eivers, E., E. Ryan, and A. Brinkley. 2000. Characteristics of early school leavers: Results of the research strand of the 8-15 -year old early school leavers initiative. Dublin: Educational Research Centre.

Eivers, E., G. Shiel, and F. Shortt. 2004. Reading literacy in disadvantaged primary schools. Dublin: Educational Research Centre.

Griffin, S., R. Case, and R. Siegler. 1994. Rightstart: Providing the central conceptual prerequisites for first formal learning of arithmetic to students at risk for school failure. In Classroom learning: Integrating cognitive theory and classroom practice, ed. K. Gilly, 25-49. Boston, MA: MIT Press.

Government of Ireland. 2004. Education for Persons with Special Educational Needs Act. Dublin: The Stationery Office. 
Kellaghan, T. 2002. Approaches to problems of educational disadvantage. In Primary education: Ending disadvantage, proceedings and action plan of national forum. Dublin: St. Patrick's College.

Lambe, S. 1997. Longitudinal study of youth labour markets. Melbourne, AU: Australian Council of Educational Research.

Lewis, M., and P. Archer. 2003. Early start evaluation. Report on observation visits to schools. Report to the Department of Education and Science, Dublin: ERC.

Mc Carthy, J., and D. Burns. 2005. Mathematics- the Cinderella subject of learning support. Learn, Journal of the Irish Learning Support Association 27: 153-8.

Morgan, M., R. Flanagan, and T. Kellaghan. 2001. A study of non-completion in undergraduate university courses. Dublin: Higher Education Authority.

Moses, R.P. 2001. Radical equations: Math literacy and civil rights. Boston, MA: Beacon Press.

National Council for Special Education. 2006. Implementation report: Plan for the phased implementation of the EPSEN Act 2004. Trim, County Meath, Republic of Ireland: National Council for Special Education.

National Council of Teachers of Mathematics. 2005. Equity in school mathematics education: How can research contribute? Journal for Research in Mathematics Education 36, no. 2: 92-100.

National Research Council. 1989. Everybody counts: A report to the nation on the future of mathematics education. Washington, DC: National Research Council.

Schoenfeld, A.H. 2002. Making mathematics work for all children: Issues of standards, testing and equity. Educational Researcher 31, no. 1: 13-25.

Shiel, G., and M. Morgan. 1998. Study of remedial education in Irish primary schools. Dublin: Educational Research Centre.

Shiel, G., and D. Kelly. 2001. The 1999 National Assessment of Mathematics AchievementSummary Report. Dublin: Educational Research Centre.

Shiel, G., P. Surgenor, S. Close, and D. Millar. 2006. The 2004 National Assessment of Mathematics Achievement. Dublin: Educational Research Centre.

Surgenor, P., and G. Shiel. 2008. Parity of provision? Learning support for English and mathematics in Irish primary schools. Irish Educational Studies 27, no. 2: 107-19.

Volmink, J. 1994. Mathematics by all. In Cultural perspectives on the mathematics classroom, ed. S. Lerman, 51-68. Dordrecht, NL: Kluwer Academic Publishers.

Weir, S. 2003. The evaluation of Breaking the Cycle: A follow-up of the achievements of $6^{\text {th }}$ class pupils in urban schools in 2003. Dublin: Educational Research Centre. 